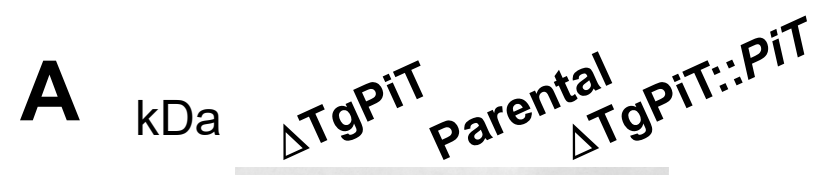

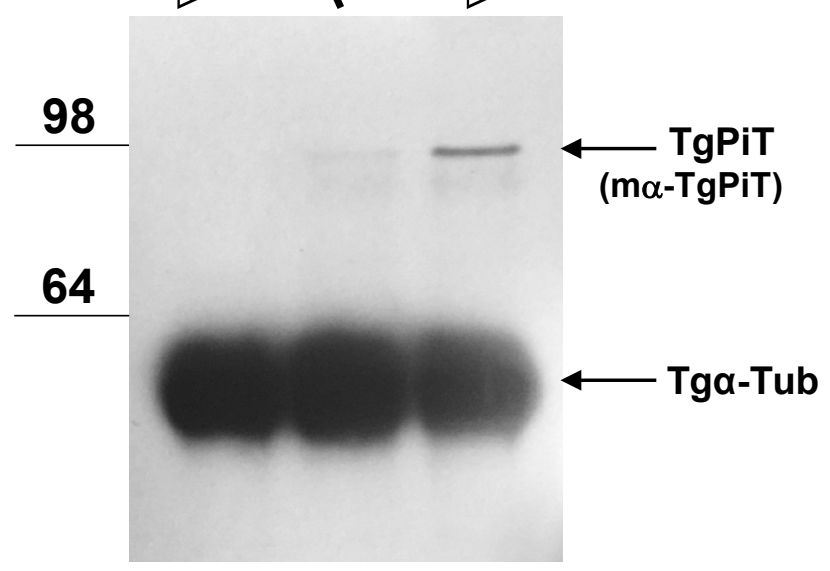

B

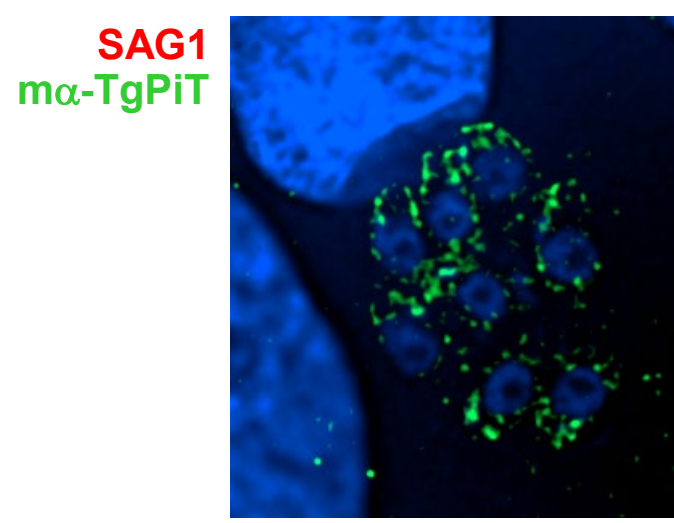

\section{$\Delta \mathrm{TgPiT}: P i T$}

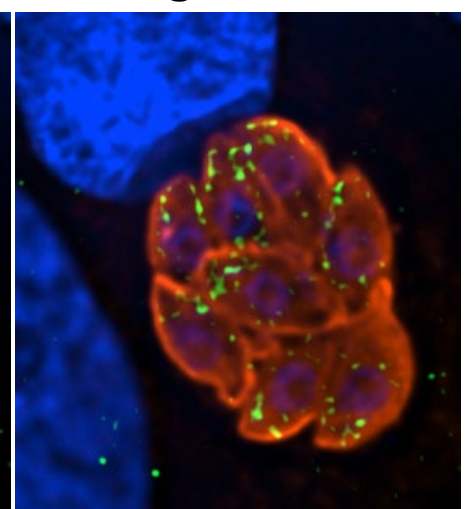

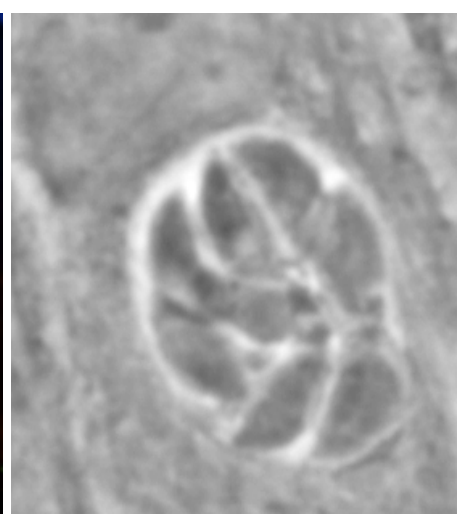

C

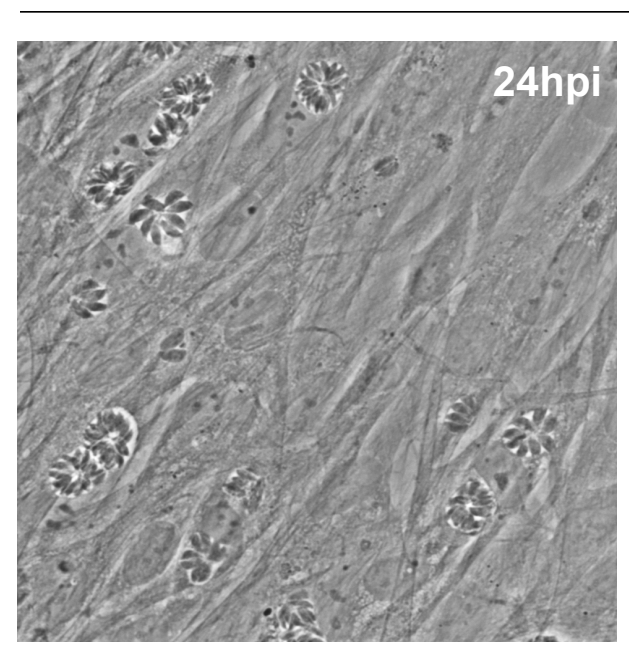

Parental

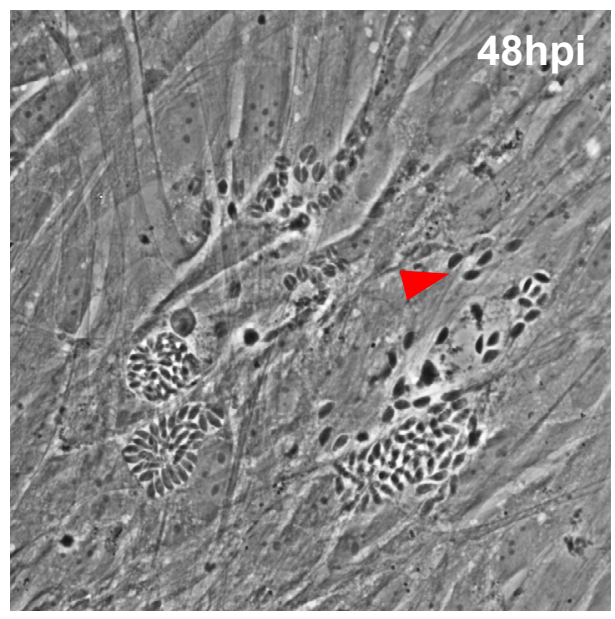

$\Delta$ TgPiT::PiT

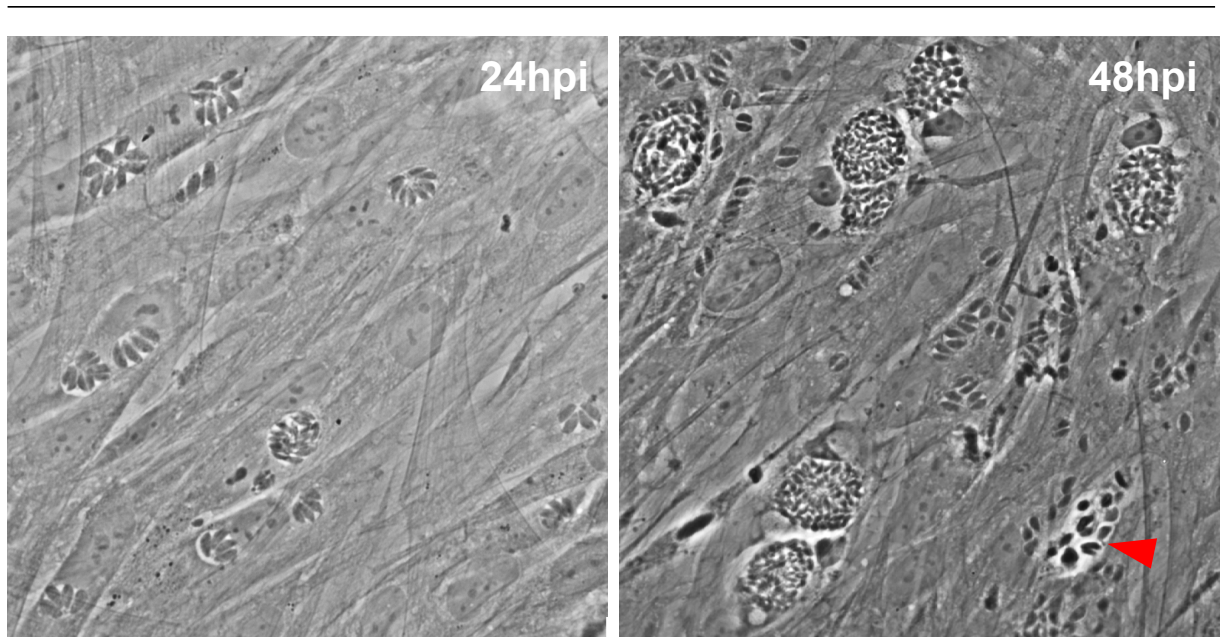

D

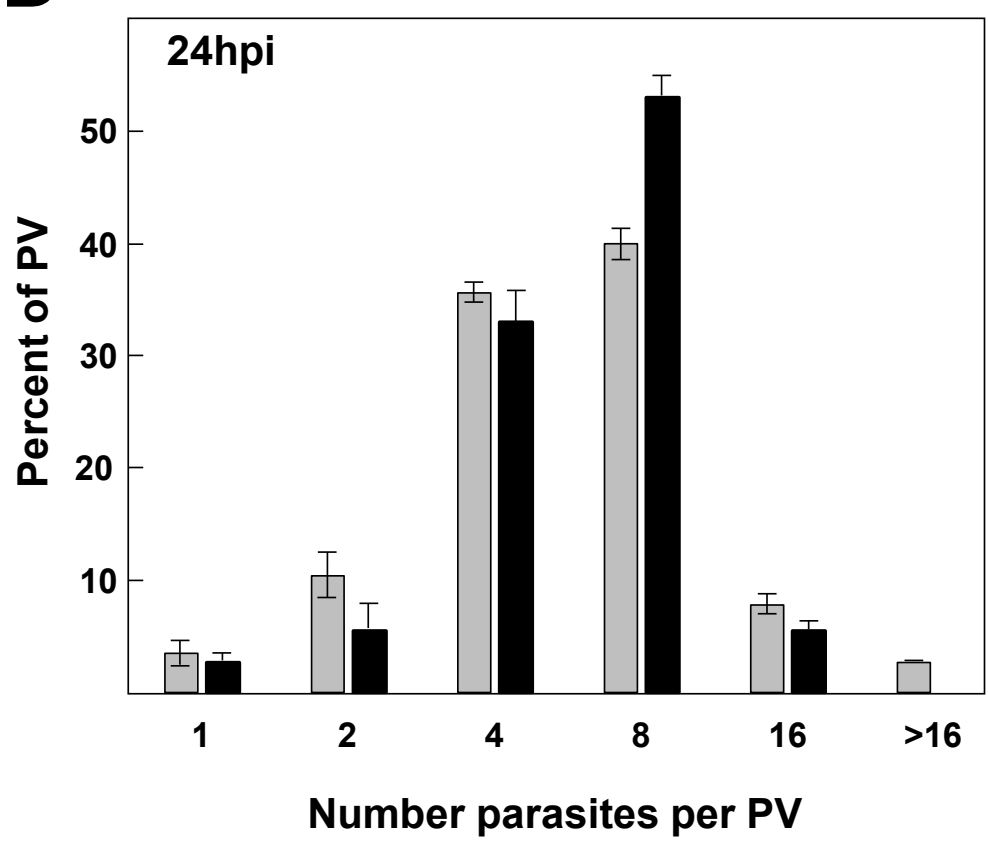

S5 Fig. Phenotype of TgPiT::PiT parasites
$\Delta$ TgPiT::PiT

Parental
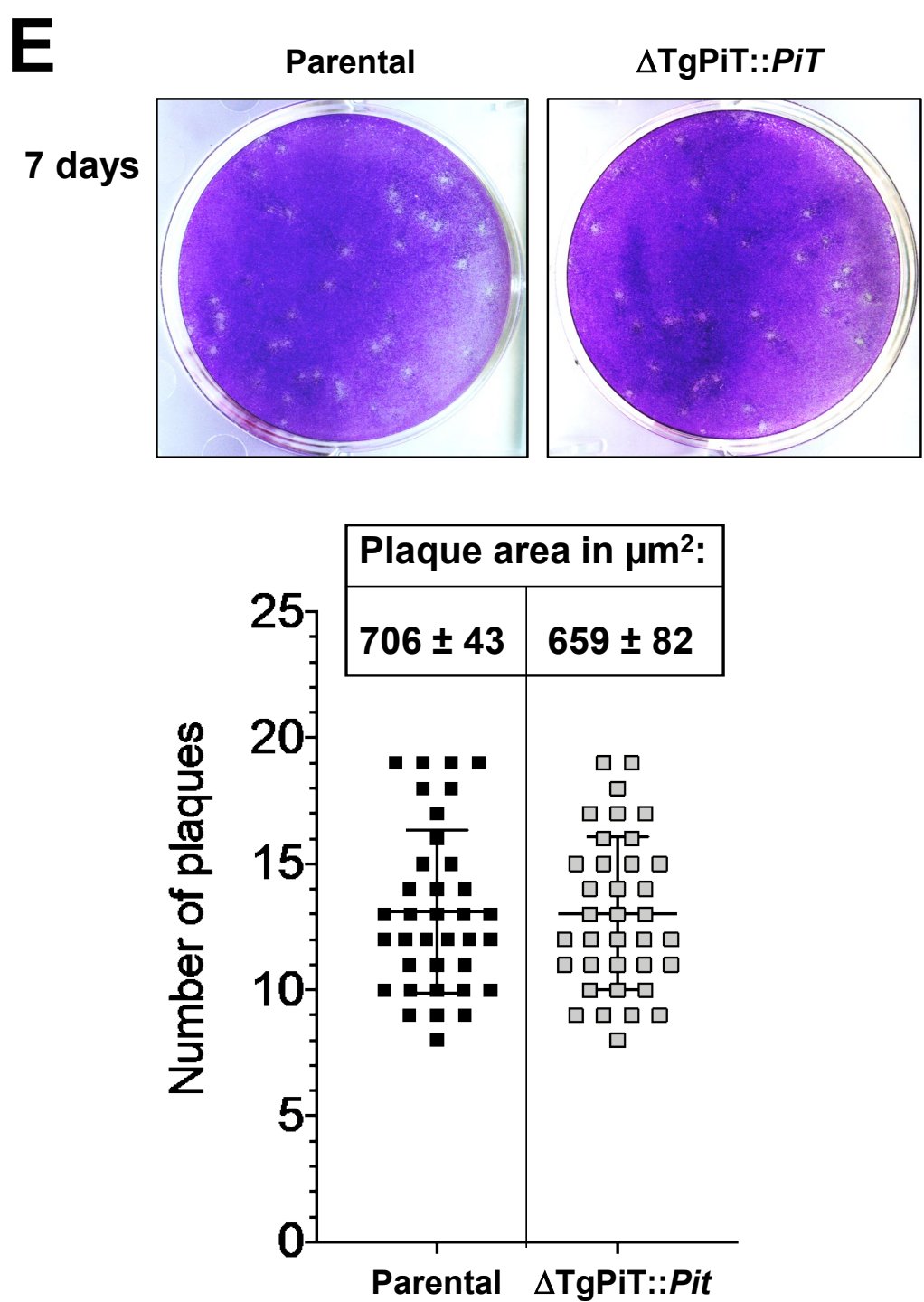